\title{
Association Behavior of Amphiphilic ABA Triblock Copolymer Composed of Poly(2-methoxyethyl acrylate) (A) and Poly(eth- ylene oxide) (B) in Aqueous Solution
}

\author{
Yoko Mizoue ${ }^{1}$, Kazutoshi Haraguchi ${ }^{2}$, Shin-ichi Yusa ${ }^{1, *}$ \\ 1 Department of Applied Chemistry, Graduate School of Engineering, University of Hyogo, 2167 Shosha, \\ Himeji, Hyogo 671-2280, Japan; ym85725@gmail.com \\ 2 College of Industrial Technology, Nihon University, 1-2-1 Izumicho, Narashino, Chiba, Japan; haragu- \\ chi.kazutoshi@nihon-u.ac.jp \\ * Correspondence: yusa@eng.u-hyogo.ac.jp; Tel.: +81-79-267-4954; Fax: +81-79-266-8868
}

\begin{abstract}
Poly(2-methoxyethyl acrylate) (PMEA) and poly(ethylene oxide) (PEO) have protein-antifouling properties and blood compatibility. ABA triblock copolymers (PMEA $n$-PEO11340-PMEA $n$ $\left(\mathrm{MEOM}_{n}\right)$ ) were prepared using single-electron transfer-living radical polymerization (SET-LRP) using a bifunctional PEO macroinitiator. Two types of $\mathrm{MEOM}_{n}$ composed of PMEA blocks with a degree of polymerization ( $\mathrm{DP}=n$ ) of 85 and 777 were prepared using the same $\mathrm{PEO}$ macroinitiator. $\mathrm{MEOM}_{n}$ formed flower micelles with a hydrophobic PMEA (A) core and hydrophilic PEO (B) loop shells in diluted water with a similar appearance to petals. The hydrodynamic radii of MEOM 85 and MEOM777 were 151 and $108 \mathrm{~nm}$, respectively. The PMEA block with a large DP formed a tightly packed core. The aggregation number $\left(N_{\text {agg }}\right)$ of the PMEA block in a single flower micelle for MEOM85 and MEOM777 was 156 and 164, respectively, which were estimated using a light scattering technique. The critical micelle concentrations (CMCs) for MEOM85 and MEOM777 were 0.01 and $0.002 \mathrm{~g} / \mathrm{L}$, respectively, as determined by the light scattering intensity and fluorescence probe techniques. The size, $N_{\text {agg, }}$ and CMC for MEOM85 and MEOM777 were almost the same independent of hydrophobic DP of the PMEA block.
\end{abstract}

Keywords: flower-like micelle; triblock copolymer; amphiphilic copolymer; single-electron transferliving radical polymerization; poly(ethylene oxide)

\section{Introduction}

Amphipathic block copolymers form interpolymer aggregates because of the hydrophobic interactions of hydrophobic blocks in water [1]. Generally, amphipathic AB diblock copolymers form core-shell spherical polymer micelles in water. ABA triblock copolymers with two hydrophobic A blocks at both ends of the central B block form flowerlike micelles caused by interpolymer aggregation in water [2]. The hydrophobic A blocks aggregate to form a core, and the hydrophilic B blocks form loop shape shells with a similar appearance to petals on the surface of the core to form flower micelles. The flower micelles are bridged when the hydrophobic A blocks in the ABA triblock copolymer are incorporated into separate cores in flower micelles. With increasing polymer concentration $\left(C_{\mathrm{P}}\right)$, the number of bridges between the flower micelles increases to form a gel [3]. The polymers increase the viscosity of the aqueous solution to form interpolymer aggregates, which can then be applied as associative thickeners with a small amount of addition [4]. For example, flower micelles formed from ABA triblock copolymers have been applied as associative thickeners [5]. Associative thickeners are used in water-based paints, coatings, personal care goods, and adhesive agents [6].

The hydrophilic shells on the surface of polymer micelles formed from amphipathic block copolymers stabilize the micelle structure and maintain their dispersion stability in 
solution [7]. Polymer micelles formed from high molecular weight polymers generally have a lower critical micelle concentration (CMC) and higher colloidal stability than those formed from low molecular weight surfactants [8]. The CMC of amphipathic diblock copolymers depends on the ratio of the hydrophobic to hydrophilic block lengths. CMC decreases with increasing hydrophobic block chain length for a constant hydrophilic block chain length in the diblock copolymer [9]. With ABA triblock copolymers, the CMC also decreases with increasing hydrophobic block chain length [10].

Single-electron transfer-living radical polymerization (SET-LRP) is a method for controlled radical polymerization using a copper catalyst [11]. A copper catalyst is widely used as an inorganic electron donor reagent for organic and polymer syntheses (Figure S1). SET-LRP can be performed at low temperatures, e.g., room temperature, because of the low activation energy [12]. Poly(ethylene oxide) (PEO) is often used as a hydrophilic block in amphipathic ABA triblock copolymers because it can form flower micelles easily $[13,14]$. Furthermore, PEO is widely used in biomedical and biomaterial fields owing to its biocompatibility [15]. 2-Methoxyethyl acrylate (MEA) is an acrylate monomer that can be polymerized by radical polymerization [16]. Poly(2-methoxyethyl acrylate) (PMEA) is highly blood compatible because it has a protein-antifouling effect, and platelets cannot adhere easily to PMEA $[17,18]$. PMEA forms an intermediate water layer on its surface to suppress protein adsorption [19]. Furthermore, PMEA can be applied as coatings on various substrates because PMEA can be soluble in organic solvents, water-insoluble, transparent, and adhesive [20]. Owing to the excellent properties of PMEA, it is also used as a coating material for artificial organs [21]. Haraguchi et al [22, 23]. have reported protein antifouling and blood compatible coatings using amphiphilic ABA triblock copolymers composed of hydrophobic PMEA (A) and hydrophilic poly( $N, N$-dimethylacrylamide) (B). The hydrophobic PMEA (A) blocks show good adhesion to both organic and inorganic substrates.

In this study, ABA triblock copolymers (PMEA $n$-PEO11340-PMEA $\left.{ }_{n}\left(\mathrm{MEOM}_{n}\right)\right)$ were prepared by SET-LRP to polymerize MEA using a bifunctional PEO macroinitiator at both chain ends. Especially, we have interested in the association behavior of ABA triblock copolymers with long PEO (B) block in water. $\mathrm{MEOM}_{n}$ was composed of a hydrophobic PMEA (A) block and a hydrophilic PEO (B) block. In water, $\mathrm{MEOM}_{n}$ formed flower micelles with a hydrophobic PMEA core and PEO loop-shaped shells (Figure 1). The associative behavior of the flower micelles formed from $\mathrm{MEOM}_{n}$ in dilute aqueous solutions was examined using dynamic light scattering (DLS), static light scattering (SLS), transmission electron microscopy (TEM), and fluorescence probe techniques.

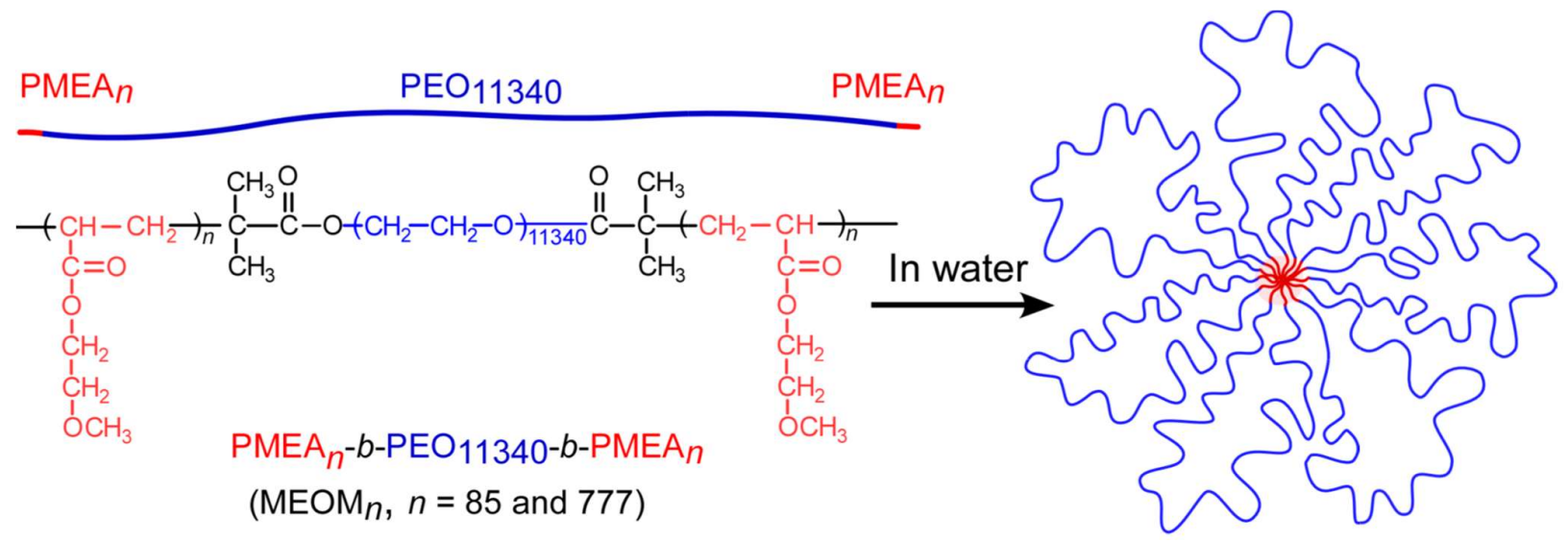

Figure 1. Conceptual illustration of flower micelles formed from $\operatorname{MEOM}_{n}(n=85$ and 777). 


\section{Materials and Methods}

\subsection{General}

Tris(2-(dimethylamino)ethyl)amine (Me6TREN, 97\%) was obtained from Sigma-Aldrich (St. Louis, MO, USA). Copper bromide $(\mathrm{CuBr}, 95.0 \%)$ was supplied by Kishida Chemical (Osaka, Japan). Ethanol (99.5\%), tetrahydrofuran (THF, 99.5\%), and cetylpyridinium chloride (90\%) were purchased from Fujifilm Wako Pure Chemical (Osaka, Japan). All chemicals were used as received. 2-Methoxyethyl acrylate (MEA, 98.0\%) from Fujifilm Wako Pure Chemical (Osaka, Japan) was treated with an inhibitor-remover prepacked column from Sigma-Aldrich (St. Louis, MO, USA) prior to use. PEO-based macroinitiator (PEO-Br) was prepared and purified in accordance with the literature [24]. Number average molecular weight $\left(M_{n}(\mathrm{GPC})\right)$ and molecular weight distribution $\left(M_{\mathrm{w}} / M_{\mathrm{n}}\right)$ estimated from gel-permeation chromatography (GPC) for PEO-Br were $4.64 \times 10^{5} \mathrm{~g} / \mathrm{mol}$ and 1.23, respectively. The degree of polymerization (DP) for PEO-Br was 11,300. Pyrene (97\%) from Fujifilm Wako Pure Chemical (Osaka, Japan) was recrystallized from methanol. Water was purified using an ion-exchange column system.

\subsection{Preparation of $\mathrm{MEOM}_{n}(n=85$ and 777$)$}

MEOM85 was prepared via SET-LRP (Scheme S1). Me6TREN (2.13 mg, $3.01 \mu \mathrm{mol}$ ) was dissolved in water $(1.00 \mathrm{~mL})$ and stirred under an argon atmosphere for $10 \mathrm{~min}$. $\mathrm{CuBr}$ $(2.96 \mathrm{mg}, 20.6 \mu \mathrm{mol})$ was then added, and the mixture was stirred for $10 \mathrm{~min}$. PEO-Br $\left(\mathrm{Mn}(\mathrm{GPC})=4.64 \times 10^{5} \mathrm{~g} / \mathrm{mol}, 1.50 \mathrm{~g}, 3.01 \mu \mathrm{mol}\right)$ and MEA (420 mg, $3.22 \mathrm{mmol}$ ) were dissolved in water $(21.3 \mathrm{~mL})$. The aqueous $\mathrm{CuBr} / \mathrm{Me}$ TREN solution was added to an aqueous PEO-Br and MEA solution under an argon atmosphere. The reaction solution was stirred for $71 \mathrm{~h}$ under an argon atmosphere at room temperature. The conversion of MEA was $16.8 \%$, which was estimated by ${ }^{1} \mathrm{H}$ nuclear magnetic resonance (NMR) spectroscopy before purification. The polymerization mixture was dialyzed against pure water for three days, and the polymer (MEOM85) was collected by freeze-drying $(0.889 \mathrm{~g}, 46.3 \%)$. DP of the PMEA block was 85 , as estimated from the ${ }^{1} \mathrm{H}$ NMR spectrum. The $M \mathrm{n}(\mathrm{GPC})$ and $M_{\mathrm{w}} / \mathrm{Mn}_{\mathrm{n}}$ estimated from GPC were $5.41 \times 10^{5} \mathrm{~g} / \mathrm{mol}$ and 1.17 , respectively.

MEOM777 was prepared using the same procedure $(2.42 \mathrm{~g}, 63.7 \%)$. The conversion of MEA before purification was $34.9 \%$, according to ${ }^{1} \mathrm{H}$ NMR spectroscopy. DP of the PMEA block was 777 , as estimated from the ${ }^{1} \mathrm{H}$ NMR spectrum. The $M_{\mathrm{n}}(\mathrm{GPC})$ and $M_{\mathrm{w}} / M_{\mathrm{n}}$ were $4.91 \times 10^{5} \mathrm{~g} / \mathrm{mol}$ and 1.26 , respectively.

\subsection{Preparation of MEOM777 aqueous solution}

MEOM777 $(5.86 \mathrm{mg}, 8.35 \mu \mathrm{mol})$ was dissolved in THF $(6.02 \mathrm{~mL})$, and the $C_{\mathrm{p}}$ was adjusted to $1.00 \mathrm{~g} / \mathrm{L}$. The THF solution was dialyzed against pure water for two days to remove THF. After dialysis, the aqueous solution was diluted with water to be $C_{\mathrm{p}}=0.10 \mathrm{~g} / \mathrm{L}$.

\subsection{Measurements}

${ }^{1} \mathrm{H}$ NMR spectroscopy was performed using a Bruker (Billerica, MA, USA) DRX-500 and JEOL (Tokyo, Japan) JNM-ECZ400R at $25^{\circ} \mathrm{C}$. The water suppression by gradient-tailored excitation (Watergate) with a double pulse field gradient spin echo pulse sequence was used for the $\mathrm{D}_{2} \mathrm{O}$ solutions to suppress the water signal. Water suppression by a gradient-tailored excitation (WATERGATE) method was used for the $\mathrm{D}_{2} \mathrm{O}$ sample to reduce the water signal. The GPC measurements were conducted at $40^{\circ} \mathrm{C}$ using a Shodex (Tokyo, Japan) DS-4 pump, a Shodex GF-7M column, and a Shodex RI-101 refractive index detector. THF was used as the eluent with a flow rate of $1.0 \mathrm{~mL} / \mathrm{min} . M_{n}(\mathrm{GPC})$ and $M_{\mathrm{w}} / M_{\mathrm{n}}$ were determined using standard polystyrene samples. The samples were analyzed by attenuated total reflection-Fourier-transform infrared (ATR-FTIR, FT/IR-4200, Jasco, Tokyo, Japan) spectroscopy. DLS measurements were performed at $25^{\circ} \mathrm{C}$ using a Malvern (Malvern, UK) Zetasizer nano ZS at a scattering angle of $173^{\circ}$. The data were analyzed using a 
Malvern (Malvern, UK) Zetasizer Software package 7.11 to determine the hydrodynamic radius $(R \mathrm{~h})$, light scattering intensity (LSI), and polydispersity (PDI). SLS measurements were taken at $25^{\circ} \mathrm{C}$ using an Otsuka Electronics (Osaka, Japan) DLS-7000. The weightaverage molecular weight $\left(M_{\mathrm{w}}(\mathrm{SLS})\right)$ was calculated from Debye plots. The refractive index increment $\left(\mathrm{d} n / \mathrm{d} C_{\mathrm{p}}\right)$ was determined using an Otsuka Electronics (Osaka, Japan) DRM-3000 differential refractometer at $25^{\circ} \mathrm{C}$. Transmission electron microscopy (TEM, JEM-2100, Jeol, Tokyo, Japan) was performed at an acceleration voltage of $160 \mathrm{kV}$. The TEM samples were prepared by placing a drop of the sample solution on a copper grid coated with a form bar, and the samples were stained with a sodium phosphotungstate aqueous solution. The samples were dried for one day under reduced pressure. Fluorescence measurements were taken using a Hitachi High-Tech (Tokyo, Japan) F-2500 fluorescence spectrophotometer. The pyrene aqueous solutions $\left(6.0 \times 10^{-7} \mathrm{M}\right)$ were excited at $334 \mathrm{~nm}$; the excitation and emission slit widths were 20 and $2.5 \mathrm{~nm}$, respectively.

\section{Results and Discussion}

\subsection{Characterization}

$\mathrm{MEOM}_{n}$ was prepared by SET-LRP using MEA and PEO-Br macroinitiator. The ${ }^{1} \mathrm{H}$ $\mathrm{NMR}$ spectra for $\mathrm{PEO}-\mathrm{Br}$ and $\mathrm{MEOM}_{n}$ were measured in $\mathrm{CDCl}_{3}$ (Figure 2). The terminal groups in PEO-Br could not be observed clearly because of the low signal intensity. The integral intensities of the PMEA pendant methylene protons at $3.3 \mathrm{ppm}(e)$ and the PEO main chain methylene protons at 3.5-4.0 ppm (f) were compared to estimate the DP (NMR $=n$ ) of one end of the PMEA block in $\mathrm{MEOM}_{n}$. The DP(NMR) values for MEOM85 and MEOM777 were 85 and 777, respectively (Table 1).

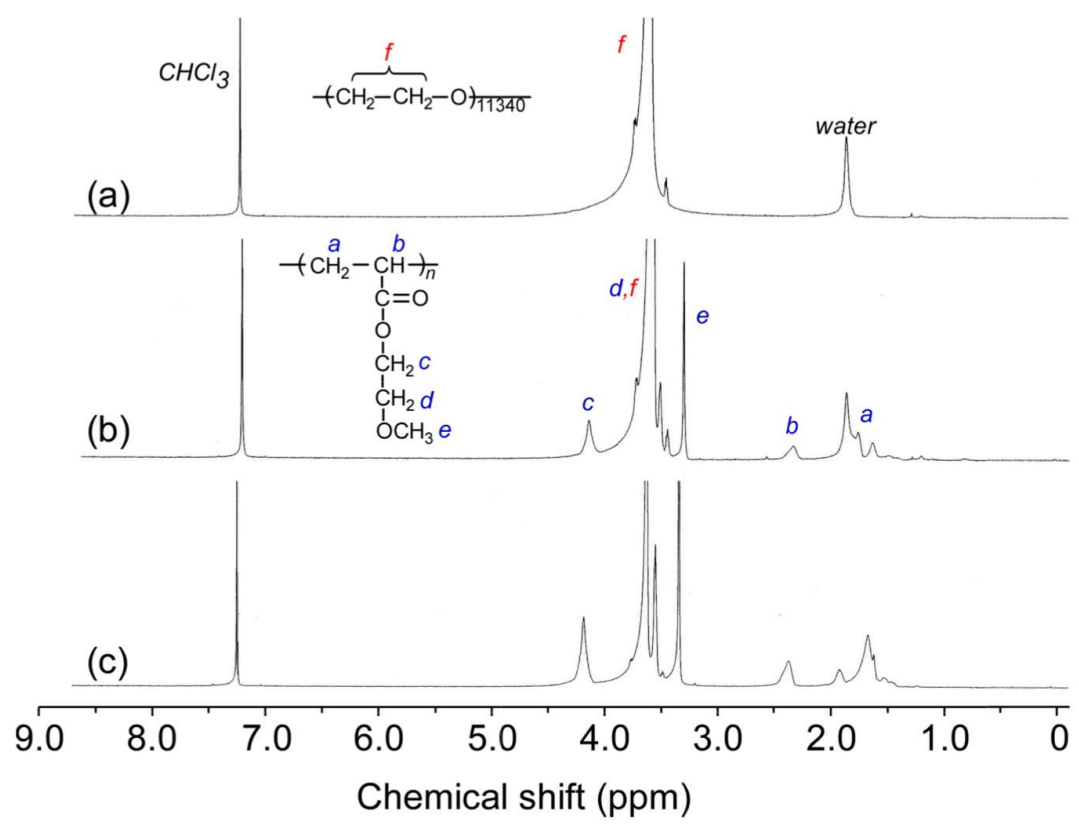

Figure 2. ${ }^{1} \mathrm{H}$ NMR spectra of (a) PEO-Br, (b) MEOM85, and (c) MEOM777 in $\mathrm{CDCl}_{3}$. 
Table 1. Characteristics of polymers.

\begin{tabular}{|c|c|c|c|c|c|c|}
\hline Sample & $\begin{array}{c}M_{\mathrm{n}} \text { (theo) } \\
\quad \times 10^{5}\end{array}$ & $\mathrm{DP}$ (theo) & $\begin{array}{c}M_{\mathrm{n}}(\mathrm{NMR}) \\
\times 10^{5}\end{array}$ & DP(NMR) & $\begin{array}{c}M_{\mathrm{n}}(\mathrm{GPC}) \\
\times 10^{5}\end{array}$ & $\begin{array}{r}M_{\mathrm{w}} / M_{\mathrm{n}} \\
(\mathrm{GPC})\end{array}$ \\
\hline PEO-Br & $5.00^{a}$ & $11340^{a}$ & 5.00 & - & 4.64 & 1.23 \\
\hline $\mathrm{MEOM}_{85}$ & 5.11 & $86^{b}$ & 5.22 & $85^{b}$ & 5.41 & 1.17 \\
\hline MEOM777 & 7.65 & $1020^{b}$ & 7.02 & $777^{b}$ & 4.91 & 1.26 \\
\hline
\end{tabular}

${ }^{a}$ These values were provided by the supplier.

${ }^{b}$ Degree of polymerization of one end of PMEA.

The theoretical DP(theo) and number average molecular weight $\left(M_{\mathrm{n}}(\right.$ theo $\left.)\right)$ can be calculated from the following equations:

$$
\begin{aligned}
& \mathrm{DP}(\text { theo })=\frac{[\mathrm{M}]_{0}}{[\mathrm{Br}]_{0}} \times \frac{\text { Conversion }(\%)}{100} \\
& M_{\mathrm{n}}(\text { theo })=\mathrm{DP}(\text { theo }) \times M_{\mathrm{n}}+M_{\mathrm{PEO}}
\end{aligned}
$$

where $[\mathrm{M}]_{0}$ and $[\mathrm{Br}]_{0}$ are the initial concentrations of the monomer and bromine atoms at the PEO-Br chain ends, respectively, and $M \mathrm{~m}$ and MPEO are the molecular weights of the monomer and PEO, respectively. The DP(theo) values of MEOM85 and MEOM777 were 86 and 1020, respectively. These theoretical values were close to the DP(NMR) values. GPC was performed for $\mathrm{MEOM}_{n}$ using THF as an eluent (Figure S2). The structure of $\mathrm{MEOM}_{n}$ could be controlled because the $M_{\mathrm{w}} / M_{\mathrm{n}}$ values estimated from GPC were less than 1.3. However, the retention time for the GPC elution curves of $\mathrm{MEOM}_{n}$ was similar to that of PEO-Br. Unexpected interactions may have occurred between the $\mathrm{MEOM}_{n}$ and GPC column, and polystyrene was used as the standard that may have impeded a correct estimation of the $M_{n}(\mathrm{GPC})$ [25].

ATR-FTIR was performed to characterize the chemical structure of $\mathrm{MEOM}_{n}$ (Figure S3). The $\mathrm{C}=\mathrm{O}$ vibration stretching peak was observed at $1700 \mathrm{~cm}^{-1}$ for $\mathrm{MEOM}_{n}$, whereas the peak could be observed for PEO-Br. The peak intensity at $1700 \mathrm{~cm}^{-1}$ increased with increasing DP of the PMEA block in $\operatorname{MEOM}_{n}$. These results confirmed that MEOMn had been prepared.

\subsection{Association behavior of $M E O M_{n}$}

The $R_{h}$ distributions of the flower micelles formed from $\mathrm{MEOM}_{n}$ in water were examined by DLS (Figure 3). MEOM777 could not dissolve directly in water because of its long hydrophobic PMEA blocks. Therefore, an aqueous solution was prepared to dialyze the THF solution of MEOM777 against water. In contrast, MEOM85 could dissolve directly in water. The $R_{\mathrm{h}}$ values of flower micelles obtained after directly dissolving them in water and after the dialysis method were compared to confirm the difference between the preparation methods of the MEOM 85 aqueous solutions (Figure S4). The $R_{\mathrm{h}}$ values for MEOM 85 prepared by direct dissolution in water and the dialysis method were 151 and $144 \mathrm{~nm}$, respectively, which are similar. Therefore, flower micelles formed from MEOM 85 regardless of the solution preparation method. The association state of MEOM 85 that was easily soluble in water reach to the lowest association energy independent of the dissolution 
methods. Unless noted otherwise, the MEOM85 aqueous solution was prepared using the direct dissolution method. The $R_{h}$ distributions for $\mathrm{MEOM}_{n}$ in water were unimodal. The $R_{\mathrm{h}}$ values for MEOM 85 and MEOM777 were 144 and $108 \mathrm{~nm}$, respectively. The DP of the hydrophobic PMEA block in MEOM777 was larger than that in MEOM85, but $R_{\mathrm{h}}$ of MEOM777 was smaller than that of MEOM85. As the DP of the PMEA block in MEOMn increased, the hydrophobic interaction became stronger to form a more compact core of the flower micelle. The PDI values for MEOM 85 and MEOM777 were 0.166 and 0.211 , respectively. MEOM85 formed more uniformly sized flower micelles than MEOM777.

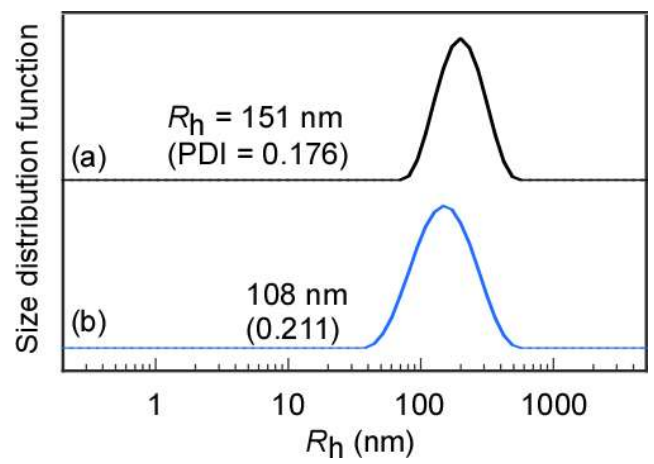

Figure 3. Hydrodynamic radius $\left(R_{\mathrm{h}}\right)$ distributions of $(\mathrm{a}) \mathrm{MEOM} 85$ and $(\mathrm{b}) \mathrm{MEOM} 777$ in water at $C_{\mathrm{p}}=$ $0.1 \mathrm{~g} / \mathrm{L}$.

Table 2. Characteristics of $\mathrm{MEOM}_{n}$ flower-like micelles in water.

\begin{tabular}{cccccccc}
\hline Sample & $\begin{array}{c}M_{\mathrm{w}}(\mathrm{SLS}) \mathrm{a} \times \\
10^{-7}(\mathrm{~g} / \mathrm{mol})\end{array}$ & $\begin{array}{c}R_{\mathrm{g}}{ }^{\mathrm{a}} \\
(\mathrm{nm})\end{array}$ & $\begin{array}{c}R_{\mathrm{h}}{ }^{\mathrm{b}} \\
(\mathrm{nm})\end{array}$ & $R_{\mathrm{g}} / R_{\mathrm{h}}$ & $\begin{array}{c}R_{\mathrm{TEM}^{\mathrm{c}}} \\
(\mathrm{nm})\end{array}$ & $\begin{array}{c}N_{\mathrm{agg}} \\
(\mathrm{SLS}){ }^{\mathrm{d}}\end{array}$ & $\begin{array}{c}\Phi_{\mathrm{H}} \times 10^{2} \\
(\mathrm{~g} / \mathrm{mL})\end{array}$ \\
\hline MEOM$_{85}$ & 4.75 & 141 & 151 & 0.934 & 42.4 & 156 & 0.547 \\
MEOM$_{777}$ & 7.27 & 164 & 108 & 1.52 & 59.2 & 164 & 2.29
\end{tabular}

a Estimated from SLS measurements; ${ }^{\mathrm{b}}$ estimated from DLS measurements; ${ }^{\mathrm{c}}$ estimated from TEM; d calculated from $2 M_{\mathrm{w}}(\mathrm{SLS}) /\left(M_{\mathrm{n}}(\mathrm{NMR}) \times M_{\mathrm{w}} / M_{\mathrm{n}}\right)$.

The structure of flower micelles formed from $\mathrm{MEOM}_{n}$ in water was confirmed by SLS (Figure S5). The apparent weight-average molecular weight ( $M_{\mathrm{w}}(\mathrm{SLS})$ ) and radius of gyration $\left(R_{\mathrm{g}}\right)$ were obtained from the SLS measurements. The refractive index increment $\left(\mathrm{d} n / \mathrm{d} C_{\mathrm{p}}\right)$ required to determine $M_{\mathrm{w}}(\mathrm{SLS})$ was obtained using a differential refractometer. The $\mathrm{d} n / \mathrm{d} C_{\mathrm{p}}$ values for MEOM 85 and MEOM777 were 0.138 and $0.426 \mathrm{~mL} / \mathrm{g}$, respectively. The number of PMEA chains $(N \mathrm{agg})$ forming a single flower micelle was calculated from the equation, $N_{\text {agg }}=2 M_{\mathrm{w}}(\mathrm{SLS}) /\left(M_{\mathrm{n}}(\mathrm{NMR}) \times M_{\mathrm{w}} / M_{\mathrm{n}}\right)$. The $N_{\mathrm{agg}}$ values for MEOM 85 and MEOM777 were 156 and 164, respectively (Table 2). The DP of the PMEA block in MEOM777 was approximately nine times larger than that in $\mathrm{MEOM}_{85}$, but both $N_{\text {agg }}$ values were close. The interface between the core and shell was sterically crowded with the PEO chains because the DP of the PEO block forms a loop-shaped shell as large as 11340 . The $N$ agg value was unlikely to increase above a certain number because of the congestion of the PEO shell chains on the core-shell interface. The $R_{g}$ values for MEOM85 and MEOM777 were 141 and $164 \mathrm{~nm}$, respectively. From the $R_{\mathrm{h}}$ and $R_{\mathrm{g}}$ values, the flower micelles formed from $\mathrm{MEOM}_{85}$ and MEOM${ }_{777}$ have similar size. The $R_{\mathrm{g}} / R_{\mathrm{h}}$ ratios for MEOM85 and MEOM777 were 0.934 and 1.52 , respectively. These $R_{\mathrm{g}} / R_{\mathrm{h}}$ ratios were close to one, suggesting that the shape of flower micelles was spherical [26]. The density $\left(\Phi_{\mathrm{H}}\right)$ of the micelle can be calculated from equation (3) [27]: 


$$
\Phi_{\mathrm{H}}=\frac{M_{\mathrm{w}}(\mathrm{SLS})}{N_{\mathrm{A}}}\left(\frac{4}{3} \pi R_{\mathrm{h}}{ }^{3}\right)^{-1}
$$

where $N_{\mathrm{A}}$ is Avogadro's number. The $\Phi_{\mathrm{H}}$ values for MEOM85 and MEOM777 were $5.47 \times$ $10^{-3}$ and $2.29 \times 10^{-2} \mathrm{~g} / \mathrm{mL}$, respectively. MEOM 777 with a long PMEA chain formed a tightly packed core because the $\Phi_{\mathrm{H}}$ value of MEOM777 was larger than that of MEOM85. ${ }^{1} \mathrm{H}$ NMR spectroscopy of $\mathrm{MEOM}_{n}$ was performed in $\mathrm{D}_{2} \mathrm{O}$ (Figure S6). The PEO signals were observed, but the PMEA signals were not. This observation suggests that the motion of PMEA was restricted due to the formation of the core, but the motion of PEO was not restricted.

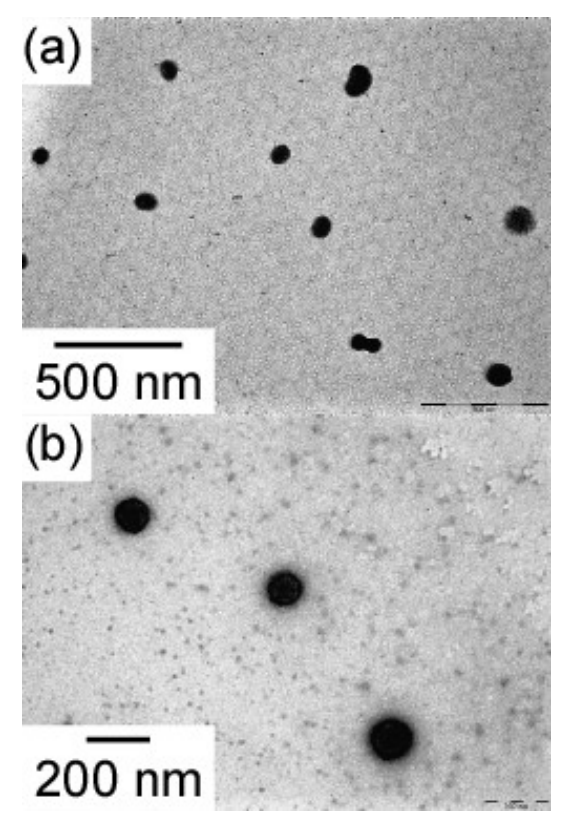

Figure 4. TEM images for (a) MEOM85 and, (b) MEOM777 in water at $C_{\mathrm{p}}=0.1 \mathrm{~g} / \mathrm{L}$.

TEM of MEOM 85 and MEOM777 in water (Figure 4) revealed spherical aggregates. The radii ( $R_{\text {TEM }}$ ) of MEOM 85 and MEOM777 estimated from TEM were 42.4 and $59.2 \mathrm{~nm}$, respec-

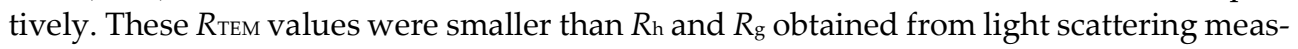
urements. The shells formed from PEO were not observed because PEO cannot be stained by sodium phosphotungstate. The core formed by the association of the PMEA blocks could be stained, as observed by TEM. Therefore, the cores observed by TEM were separated a certain distance due to the unstained PEO loop shells that cannot be observed by TEM.

\subsection{Critical Micelle Concentration (CMC) of $M E O M_{n}$}

To determine the CMC of flower micelles, the LSI for $\mathrm{MEOM}_{n}$ aqueous solutions was measured as a function of $C_{\mathrm{p}}$ (Figure 5$)$. The ratio $\left(I / I_{0}\right)$ of the LSI of the solution $(I)$ to the solvent $\left(I_{0}\right)$ was plotted as a function of $C_{\mathrm{p}}$. The $\mathrm{CMC}$ was estimated from the inflection point of the slope [28]. The CMC values for MEOM85 and MEOM777 were calculated to be 0.01 and $0.002 \mathrm{~g} / \mathrm{L}$, respectively (Table 3). 


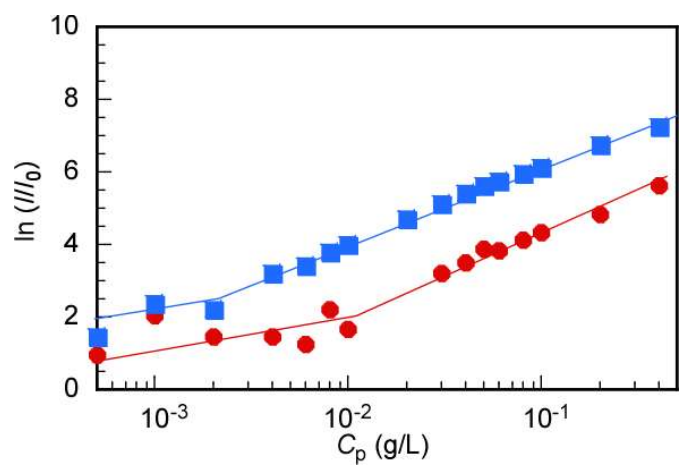

Figure 5. Light scattering intensity (LSI) ratio $\left(I / I_{0}\right)$ as a function of polymer concentration $\left(C_{\mathrm{p}}\right)$ for $\operatorname{MEOM}_{85}()_{)}$and MEOM777 $(\square)$ in aqueous solutions; $I_{0}$ is LSI of water, and $I$ is LSI of the polymer solution.
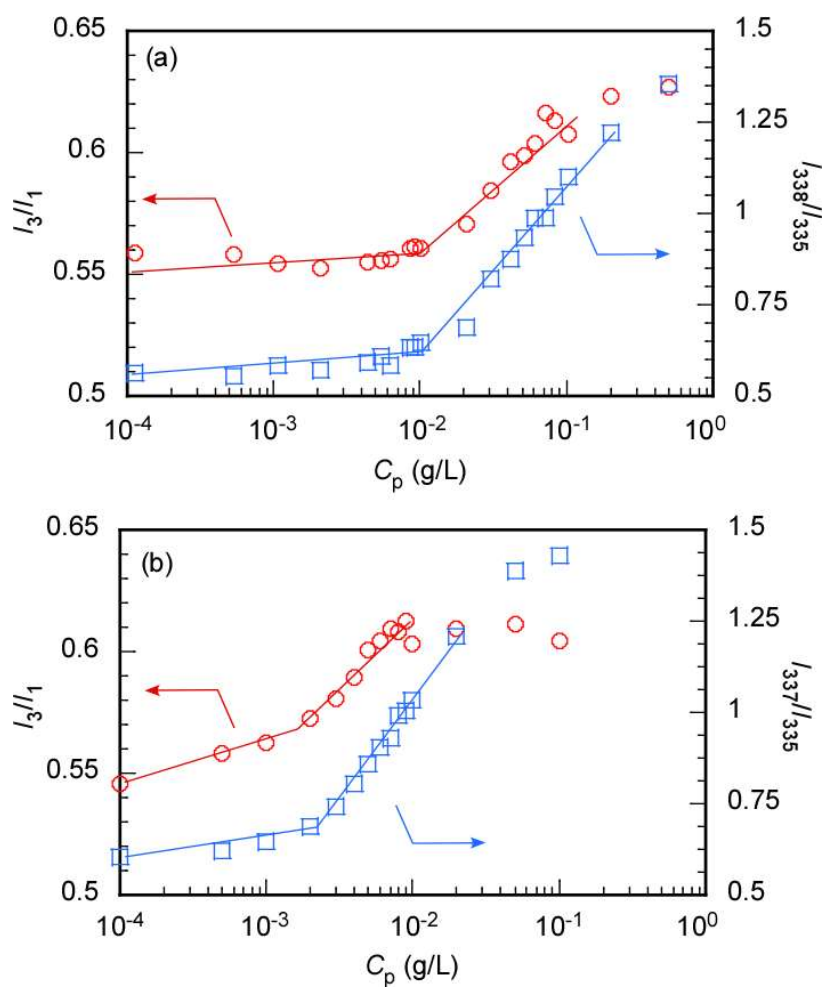

Figure 6. Pyrene fluorescence intensity ratio $\left(I_{3} / I_{1}, \bigcirc\right)$ and excitation intensity ratio $\left(I_{338} / I_{335} 、 \square\right)$ as a function of the polymer concentration $\left(C_{\mathrm{p}}\right)$ for (a) MEOM85 and (b) MEOM777 in aqueous solutions; $I_{3}$ and $I_{1}$ are the third and first vibronic peak intensities of pyrene fluoresce, and $I_{338}$ and $I_{335}$ are the peak intensities at 338 and $335 \mathrm{~nm}$ in the excitation spectra of pyrene.

The $\mathrm{CMC}$ of $\mathrm{MEOM}_{n}$ was also estimated using pyrene as a hydrophobic fluorescence probe (Figure 6$)$. The intensity ratio $\left(I_{3} / I_{1}\right)$ of the first $\left(I_{1}\right)$ to third vibronic peak $\left(I_{3}\right)$ of the pyrene fluorescence spectrum depends on the microenvironmental polarity around the pyrene molecule [29]. $I_{3} / I_{1}$ increased with decreasing microenvironmental polarity. $I_{3} / I_{1}$ was plotted as a function of $C_{\mathrm{p}}$ to determine the $\mathrm{CMC}(\mathrm{CMC}(\mathrm{Em}))$ (Figure 6). $\mathrm{CMC}(\mathrm{Em})$ was calculated from the intersections of the two tangents of the plots. The $\mathrm{CMC}(\mathrm{Em})$ values for MEOM 85 and MEOM777 were 0.01 and $0.0015 \mathrm{~g} / \mathrm{L}$, respectively. The emission maximum wavelength of the $0-0$ band in the pyrene excitation spectrum shifts to a longer wavelength when the microenvironment around the pyrene molecule becomes hydrophobic [30]. The $0-0$ band maximum wavelengths of the aqueous solutions in the presence 
and absence of $\mathrm{MEOM}_{n}$ were 338 and $335 \mathrm{~nm}$, respectively. The CMC (CMC(Ex)) was determined from a plot of $I_{338} / I_{335}$ vs. $C_{\mathrm{p}}$, where $I_{338}$ and $I_{335}$ are the emission intensities at 338 and $335 \mathrm{~nm}$, respectively. The CMC(Ex) values for MEOM 85 and MEOM777 were 0.01 and $0.002 \mathrm{~g} / \mathrm{L}$, respectively. The CMC values estimated from the LSI and fluorescence probe methods were similar.

Table 3. Critical micelle concentration (CMC) of $\mathrm{MEOM}_{n}$.

\begin{tabular}{cccc}
\hline Sample & $\begin{array}{c}\text { CMC(LSI) } \\
(\mathrm{g} / \mathrm{L})\end{array}$ & $\begin{array}{c}\mathrm{CMC}(\text { Em }) \\
(\mathrm{g} / \mathrm{L})\end{array}$ & $\begin{array}{c}\mathrm{CMC}(\mathrm{Ex}) \\
(\mathrm{g} / \mathrm{L})\end{array}$ \\
\hline MEOM $_{85}$ & 0.01 & 0.01 & 0.01 \\
MEOM$_{777}$ & 0.002 & 0.0015 & 0.002 \\
\hline
\end{tabular}

\section{Conclusions}

Amphiphilic ABA triblock copolymers, $\mathrm{MEOM}_{n}$, were prepared via SET-LRP using a bifunctional PEO-Br macroinitiator. MEOM 85 and MEOM777 were prepared with different DP of the hydrophobic PMEA blocks at the central PEO chain ends. The DP of the PMEA block in MEOM777 was approximately nine times larger than that of MEOM85. The $R_{\mathrm{h}}$ values for flower micelles formed from MEOM85 and MEOM777 in water were 151 and 108 nm, respectively. The hydrophobic PMEA blocks with a large DP in MEOM777 associated to form a densely packed core due to the strong hydrophobic interactions. The Nagg values for flower micelles formed from MEOM $\mathrm{M}_{55}$ and MEOM777 were similar. The CMC for MEOM85 and MEOM777 were 0.01 and $0.002 \mathrm{~g} / \mathrm{L}$, respectively. The CMC of MEOM777 was smaller than that of MEOM 85 because of the strong hydrophobic interactions of MEOM ${ }_{777}$. These results may come from DP of the PEO block was much larger than that of the PMEA blocks. The PEO blocks that formed the loop shells of flower micelles and the PMEA blocks that formed the core were both biocompatible. Therefore, the biocompatible flower micelles formed from $\mathrm{MEOM}_{n}$ may have applications as novel drug delivery carriers. We believe that the chemical design of $\mathrm{MEOM}_{n}$ can be applied for coating on the various biomedical devices.

Supplementary Materials: Scheme S1. Synthesis of $\operatorname{MEOM}_{n}(n=85$ and 777); Figure S1. Mechanism of single-electron transfer-living radical polymerization (SET-LRP); M; monomer, P; polymer, $\mathrm{Cu}$; copper, $\mathrm{X}$; halogen, L; ligand, $k_{a c t}$; activation, $k_{\text {deact }}$; deactivation, $k_{p}$; propagation, $k_{t}$; termination; Figure S2. GPC elution curves for PEO11340-Br (---), MEOM85 (-), and MEOM777 (-) using THF as an eluent with a flow rate of $1.0 \mathrm{~mL} / \mathrm{min}$ at $40^{\circ} \mathrm{C}$; Figure S3. Attenuated total reflection (ATR) Fouriertransform infrared (FTIR) spectra for (a) PEO11340-Br, (b) MEOM85, and (c) MEOM777; Figure S4. Hydrodynamic radius $\left(R_{\mathrm{h}}\right)$ distributions for MEOM $\mathrm{M}_{85}$ aqueous solution prepared using dialysis from the THF solution against aqueous solution; the final polymer concentration $\left(C_{\mathrm{p}}\right)$ was adjusted to be $0.1 \mathrm{~g} / \mathrm{L}$; Figure S5. Debye plots for (a) MEOM 85 and (b) MEOM777 in water; Figure S6. WATERGATE ${ }^{1} \mathrm{H}$ NMR spectra in $\mathrm{D}_{2} \mathrm{O}$ for (a) MEOM85 and (b) MEOM777.

Author Contributions: Conceptualization and experimental design: K.H. and S.Y.; Experimental work and data analysis: Y.M.; writing: Y.M., K.H., and S.Y. All authors have read and agreed to the published version of the manuscript.

Funding: This work was funded by a Grant-in-Aid for Scientific Research (17H03071) from the Japan Society for the Promotion of Science (JSPS), JSPS Bilateral Joint Research Projects (JPJSBP120203509), and the Cooperative Research Program of "Network Joint Research Center for Materials and Devices (20204034)."

Conflicts of Interest: The authors declare no conflict of interest. 


\section{References}

1. Shi, Y.; Van Nostrum, C.F.; Hennink, W.E. Interfacially hydrazone cross-linked thermosensitive polymeric micelles for acidtriggered release of paclitaxel. ACS Biomater. Sci. Eng. 2015, 1, 393-404.

2. Honda, S.; Yamamoto, T.; Tezuka, Y. Topology-directed control on thermal stability: Micelles formed from linear and cyclized amphiphilic block copolymers. J. Am. Chem. Soc. 2010, 132, 10251-10253.

3. Yuan, F.; Larson, R.G. Multiscale molecular dynamics simulations of model hydrophobically modified ethylene oxide urethane micelles. J. Phys. Chem. B 2015, 119, 12540-12551.

4. Lundberg, D.J.; Brown, R.G.; Glass, J.E.; Eley, R.R. Synthesis, characterization, and solution rheology of model hydrophobicallymodified, water-soluble ethoxylated urethanes. Langmuir 1994, 10, 3027-3034.

5. Maiti, S.; Chatterji, P.R. Transition from normal to flower like micelles. J. Phys. Chem. B 2000, 104, $10253-10257$.

6. Vorobyova, O.; Yekta, A.; Winnik, M.A.; Lau, W. Fluorescent probe studies of the association in an aqueous solution of a hydrophobically modified poly(ethylene oxide). Macromolecules 1998, 31, 8998-9007.

7. Gref, R.; Lück, M.; Quellec, P.; Marchand, M.; Dellacherie, E.; Harnisch, S.; Blunk, T.; Müller, R.H. "Stealth" corona-core nanoparticles surface modified by polyethylene glycol (PEG): Influences of the corona (PEG chain length and surface density) and of the core composition on phagocytic uptake and plasma protein adsorption. Colloids Surf. B Biointerfaces 2000, 18, 301-313.

8. De Graaf, A.J.; Boere, K.W.M.; Kemmink, J.; Fokkink, R.G.; Van Nostrum, C.F.; Rijkers, D.T.S.; Van Der Gucht, J.; Wienk, H.; Baldus, M.; Mastrobattista, E.; Vermonden, T.; Hennink, W.E. Looped structure of flower like micelles revealed by ${ }^{1} \mathrm{H}$ NMR relaxometry and light scattering. Langmuir 2011, 27, 9843-9848.

9. Kelarakis, A.; Yang, Z.; Pousia, E.; Nixon, S.K.; Price, C.; Booth, C.; Hamley, I.W.; Castelletto, V.; Fundin, J. Association properties of diblock copolymers of propylene oxide and ethylene oxide in aqueous solution. The effect of $\mathrm{P}$ and $\mathrm{E}$ block lengths. Langmuir 2001, 17, 8085-8091.

10. Wang, C.H.; Hsiue, G.H. New amphiphilic poly(2-ethyl-2-oxazoline)/poly(L-lactide) triblock copolymers. Biomacromolecules 2003, 4, 1487-1490

11. Zhang, N.; Samanta, S.R.; Rosen, B.M.; Percec, V. Single electron transfer in radical ion and radical-mediated organic, materials and polymer synthesis. Chem. Rev. 2014, 114, 5848-5958.

12. Lligadas, G.; Grama, S.; Percec, V. Single-electron transfer living radical polymerization platform to practice, develop, and invent. Biomacromolecules 2017, 18, 2981-3008.

13. Najafi, M.; Kordalivand, N.; Moradi, M.A.; Van Den Dikkenberg, J.; Fokkink, R.; Friedrich, H.; Sommerdijk, N.A.J.M.; Hembury, M.; Vermonden, T. Native chemical ligation for cross-linking of flower-like micelles. Biomacromolecules 2018, 19, 3766-3775.

14. Oh, K.T.; Oh, Y.T.; Oh, N.M.; Kim, K.; Lee, D.H.; Lee, E.S. A smart flower-like polymeric micelle for pH-triggered anticancer drug release. Int. J. Pharm. 2009, 375, 163-169.

15. Baek, A.; Baek, Y.M.; Kim, H.M.; Jun, B.H.; Kim, D.E. Polyethylene glycol-engrafted graphene oxide as biocompatible materials for peptide nucleic acid delivery into cells. Bioconjug. Chem. 2018, 29, 528-537.

16. Tanaka, M.; Motomura, T.; Kawada, M.; Anzai, T.; Kasori, Y.; Shiroya, T.; Shimura, K.; Onishi, M.; Mochizuki, A. Blood compatible aspects of poly(2-methoxyethylacrylate) (PMEA)-relationship between protein adsorption and platelet adhesion on PMEA surface. Biomaterials 2000, 21, 1471-1481.

17. Steinhauer, W.; Hoogenboom, R.; Keul, H.; Moeller, M. Copolymerization of 2-hydroxyethyl acrylate and 2-methoxyethyl acrylate via RAFT: Kinetics and thermoresponsive properties. Macromolecules 2010, 43, 7041-7047.

18. Tanaka, M.; Mochizuki, A.; Ishii, N.; Motomura, T.; Hatakeyama, T. Study of blood compatibility with poly(2-methoxyethyl acrylate). Relationship between water structure and platelet compatibility in poly(2-methoxyethylacrylate-co-2-hydroxyethylmethacrylate). Biomacromolecules 2002, 3, 36-41.

19. Liu, G.; Qiu, Q.; Shen, W.; An, Z. Aqueous dispersion polymerization of 2-methoxyethyl acrylate for the synthesis of biocompatible nanoparticles using a hydrophilic RAFT polymer and a redox initiator. Macromolecules 2011, 44, 5237-5245.

20. Liu, G.; Jin, Q.; Liu, X.; Lv, L.; Chen, C.; Ji, J. Biocompatible vesicles based on PEO- $b$-PMPC/ $\alpha$-cyclodextrin inclusion complexes for drug delivery. Soft Matter 2011, 7, 662-669.

21. Mueller, X.M.; Jegger, D.; Augstburger, M.; Horisberger, J.; Von Segesser, L.K. Poly2-methoxyethylacrylate (PMEA) coated oxygenator: An ex vivo study. Int. J. Artif. Organs 2002, 25, 223-229.

22. Haraguchi, K.; Kubota, K.; Takada, T.; Mahara, S. Highly protein-resistant coatings and suspension cell culture thereon from amphiphilic block copolymers Prepared by RAFT polymerization. Biomacromolecules 2014, 15, 1992-2003.

23. Haraguchi, K.; Takehisa,T.; Mizuno, T.; Kubota, K. Antithrombogenic properties of amphiphilic block copolymer coatings: Evaluation of hemocompatibility using whole blood. ACS Biomater. Sci. Eng. 2015, 1, 352-362.

24. Filippov, S.K.; Bogomolova, A.; Kaberov, L.; Velychkivska, N.; Starovoytova, L.; Cernochova, Z.; Rogers, S.E.; Lau, W.M.; Khutoryanskiy, V.V.; Cook, M.T. Internal nanoparticle structure of temperature-responsive self-assembled PNIPAM- $b$-PEG- $b$ PNIPAM triblock copolymers in aqueous solutions: NMR, SANS, and light scattering studies. Langmuir 2016, 32, 5314-5323.

25. Meier, M.A.R.; Lohmeijer, B.G.G.; Schubert, U.S. Characterization of defined metal-containing supramolecular block copolymers. Macromol. Rapid Commun. 2003, 24, 852-857.

26. Akcasu, A.Z.; Han, C.C. Molecular weight and temperature dependence of polymer dimensions in solution. Macromolecules $1979,12,276-280$. 
27. Tahara, Y.; Sakiyama, M.; Takeda, S.; Nishimura, T.; Mukai, S.A.; Sawada, S.I.; Sasaki, Y.; Akiyoshi, K. Self-assembled nanogels of cholesterol-bearing hydroxypropyl cellulose: A thermoresponsive building block for nanogel tectonic materials. Langmuir 2016, 32, 12283-12289.

28. Topel, Ö.; Çakir, B.A.; Budama, L.; Hoda, N. Determination of critical micelle concentration of polybutadiene-block-poly(ethyleneoxide) diblock copolymer by fluorescence spectroscopy and dynamic light scattering. J. Mol. Liq. 2013, 177, 40-43.

29. Kalyanasundaram, K.; Thomas, J.K. Environmental effects on vibronic and intensities in pyrene monomer fluorescence and their application in studies of micellar systems. J. Am. Chem. Soc. 1977, 99, 2039-2044.

30. Xu, J.P.; Ji, J.; Chen, W.D.; Shen, J.C. Novel biomimetic surfactant: Synthesis and micellar characteristics. Macromol. Biosci. 2005, 5, 164-171. 